\title{
Transforming growth factor-beta and liver injury in an arginine vasopressin-induced pregnant rat model
}

\author{
Nalini Govender ${ }^{1}$, Sapna Ramdin ${ }^{1}$, Rebecca Reddy ${ }^{1}$, Thajasvarie Naicker ${ }^{2}$ \\ 'Department of Basic Medical Sciences, Faculty of Health Sciences, Durban University of Technology, Durban; ${ }^{2}$ Discipline of Optics and Imaging, Doris \\ Duke Medical Research Institute, College of Health Sciences, University of KwaZulu-Natal, Durban, South Africa
}

Objective: Approximately $30 \%$ of preeclamptic pregnancies exhibit abnormal liver function tests. We assessed liver injury-associated enzyme levels and circulating transforming growth factor beta (TGF- $\beta$ ) levels in an arginine vasopressin (AVP)-induced pregnant Sprague-Dawley rat model.

Methods: Pregnant and non-pregnant Sprague-Dawley rats $(\mathrm{n}=24)$ received AVP (150 ng/hr) subcutaneously via mini-osmotic pumps for 18 days. Blood pressure was measured, urine samples were collected, and all animals were euthanized via isoflurane. Blood was collected to measure circulating levels of TGF- $\beta 1-3$ isomers and liver injury enzymes in pregnant AVP (PAVP), pregnant saline (PS), non-pregnant AVP (NAVP), and non-pregnant saline (NS) rats.

Results: The PAVP group showed significantly higher systolic and diastolic blood pressure than both saline-treated groups. The weight per pup was significantly lower in the AVP-treated group than in the saline group $(p<0.05)$. Circulating TGF- $\beta 1-3$ isomer levels were significantly higher in the PAVP rats than in the NS rats. However, similar TGF- $\beta 1$ and TGF- $\beta 3$ levels were noted in the PS and PAVP rats, while TGF- $\beta 2$ levels were significantly higher in the PAVP rats. Circulating liver-type arginase- 1 and 5 '-nucleotidase levels were higher in the PAVP rats than in the saline group.

Conclusion: This is the first study to demonstrate higher levels of TGF- $\beta 2$, arginase, and 5'-nucleotidase activity in PAVP than in PS rats. AVP may cause vasoconstriction and increase peripheral resistance and blood pressure, thereby elevating TGF- $\beta$ and inducing the preeclampsia-associated inflammatory response. Future studies should explore the mechanisms through which AVP dysregulates liver injury enzymes and TGF- $\beta$ in pregnant rats.

Keywords: Arginase 1; Arginine vasopressin; Aspartate transaminase 1; Liver injury; Transforming growth factor beta

\section{Introduction}

Modulation of maternal immunity is challenging as it requires the

Received: August 13, 2020 · Revised: December 10, 2020 · Accepted: January 16, 2021 Corresponding author: Nalini Govender

Department of Basic Medical Sciences, Faculty of Health Sciences, Durban University of Technology, 7 Ritson Rd, Durban 4001, South Africa

Tel: +27-31-3732796 E-mail:nalinip@dut.ac.za

*This work was supported by the National Research Foundation (grant no. 107236 and 122014.).

This is an Open Access article distributed under the terms of the Creative Commons Attribution Non-Commercial License (http://creativecommons.org/licenses/by-nc/4.0/) which permits unrestricted non-commercial use, distribution, and reproduction in any medium, provided the original work is properly cited. maintenance of the homeostatic balance between acceptance of the semi-allograft fetus and immunological protection of the mother [1]. Immune anomalies within a compromised maternal-fetal system are linked to liver injury in cases of pregnancy complications such as preeclampsia (PE) $[1,2]$. Notably, $3 \%$ of pregnancies worldwide are affected by various liver disorders [3], a third (35\%) of which are a consequence of PE development, which is associated with considerable maternal and neonatal morbidity and mortality [4]. Liver damage in preeclamptic pregnancies includes hepatic arterial vasospasm and fibrin precipitation, eventually leading to lobular ischemia and hepatocyte necrosis [5]. It is believed that hepatic injury elevates transforming growth factor beta (TGF- $\beta$ ) gene expression [6]. 
PE is characterized by high blood pressure with or without proteinuria at 20 weeks of gestation [7]. Despite extensive ongoing research surrounding its development, the mechanisms responsible for its progression remain uncertain. Extensive research has focused on the role of anti-angiogenic factors such as endoglin and soluble vascular endothelial growth factor receptor (sFt-1) in favor of proangiogenic factors, such as vascular endothelial growth factor and placental growth factor (PIGF) in the development and progression of $\mathrm{PE}[8,9]$. More specifically, prior to the onset of maternal symptoms of $\mathrm{PE}$, sFt-1 elevation is accompanied by a concurrent decline in circulating PIGF levels [10].

TGF- $\beta$ is a profibrogenic, multifunctional cytokine that has 3 isoforms (TGF- $\beta 1-3$ ). It binds to transmembrane type I and type II receptors, and this binding may be enhanced by connective tissue growth factors [11]. Its co-receptor, endoglin, is a transmembrane glycoprotein expressed on endothelial and syncytiotrophoblastic cells [12], and its expression has been reported to increase during early-onset $\mathrm{PE}$ rather than late-onset $\mathrm{PE}$ compared to gestational age-matched controls [13]. This elevation does not hinder TGF- $\beta$ signaling, however; when interconnected with both onset types, it synergistically prevents the signaling of TGF- $\beta 1$ and TGF- $\beta 2$. The soluble form of endoglin decreases endothelial nitric oxide (NO) signaling by inhibiting TGF- $\beta 1$ signaling [14], resulting in the endothelial dysfunction characteristic of early-onset PE [12]. The latent form of TGF- $\beta$ is a key constituent of the extracellular matrix (ECM), an obligatory target for integrins [15]. TGF- $\beta 1$ regulates cell growth, differentiation, ECM production, and proteolytic turnover; therefore, it plays a profound role in trophoblast cell migration and invasiveness [16]. The overexpression of placental TGF- $\beta 3$ leads to deficient trophoblast invasion with consequential nonphysiological transformation of myometrial spiral arteries, a feature characteristic of PE development [17]. Moreover, its upregulation may be implicated in angiotensin II-induced target organ damage in hypertension [18].

Common pregnancy-initiated liver diseases include hemolysis, elevated liver enzymes, low platelet count syndrome (HELLP) syndrome and acute fatty liver of pregnancy. Earlier studies have suggested a role of TGF- $\beta$ in every stage of the progression of chronic liver disease, including the initial stages of liver injury that lead to inflammation and fibrosis [19]. In light of the fact that abnormal liver function tests occur in $20 \%$ to $30 \%$ of pregnancies complicated by hypertensive disorders of pregnancy such as PE [20], this study assessed liver injury enzymes with concomitant circulating levels of TGF- $\beta$ in an arginine vasopressin (AVP)-induced pregnant SpragueDawley rat model. It also attempted to correlate serum TGF- $\beta$ levels with liver injuries.

\section{Methods}

\section{Ethical considerations and animal welfare}

This study was approved by the Institutional Animal Research Ethics Committee (AREC/046/017) of University of KwaZulu-Natal (UKZN), South Africa. All procedures were conducted as described in the Approved Standard Protocols of the Animal Research Ethics Committee. Female Sprague-Dawley rats aged 10-12 weeks (weighing 160-180 g) were obtained from the Biomedical Research Unit of UKZN. All animals were housed in polycarbonate cages under standard laboratory conditions of temperature $\left(22^{\circ} \mathrm{C}-24^{\circ} \mathrm{C}\right)$, humidity $(60 \%)$ and illumination (12-hr light/dark cycles). They had ad libitum access to standard rat chow (Meadows Feeds, Pietermaritzburg, South Africa) and normal drinking water.

\section{Mating}

Daily vaginal smears were done to determine the progression of the estrous cycle. Following the confirmation of the estrous phase, two female rats were housed with a single male in polycarbonate cages for 24 hours, followed by vaginal smears 24 hours later to detect sperm and confirm fertilization.

\section{Experimental study}

Twenty-four pregnant Sprague-Dawley rats aged 10-12 weeks (160-180 g), were surgically implanted on gestational day (GD) 1 with ALZET mini-osmotic pumps (model 2004; Durect Corp., Cupertino, (A, USA) to subcutaneously deliver AVP at $150 \mathrm{ng} / \mathrm{hr}$. All rats (saline and AVP delivery groups) were anaesthetized with isoflurane and maintained on gaseous anesthesia for the implantation of the subcutaneous mini-osmotic pumps, which remained implanted until sacrifice. Physiological parameters (weight, systolic and diastolic blood pressure) were measured at GD 8, 14, and 18 using an mouse rat blood pressure tail-cuff blood pressure monitor (IITC Life Science Inc., Woodland Hills, CA, USA). The animals were categorized into four groups containing six rats each: group 1, non-pregnant with saline delivery (NS); group 2, non-pregnant with AVP delivery (NAVP); group 3, pregnant with saline delivery (PS); and group 4, pregnant with AVP delivery (PAVP). Urinary protein levels were measured by collecting 24-hour urine samples (GD 8, 14, and 18) using the M-TP Microprotein Kit (Beckman Coulter, San Jose, CA, USA). All animals were euthanized on GD 18, via anesthesia inhalation using isoflurane (Safeline Pharmaceuticals, Johannesburg, South Africa). Blood samples were collected at sacrifice via cardiac puncture and centrifuged for 15 minutes at $3,500 \mathrm{rpm}$ at $4^{\circ} \mathrm{C}$. Serum was stored at $-80^{\circ} \mathrm{C}$ to determine the circulating levels of TGF- $\beta$ and liver injury enzymes. 


\section{TGF- $\beta$ immunoassay protocol}

The transforming growth factor magnetic bead kit (catalogue No. TGFBMAG-64K-03; Merck Millipore, Darmstadt, Germany) was used to quantify the levels of TGF- $\beta 1$, TGF- $\beta 2$ and TGF- $\beta 3$, according to the manufacturer's instructions (Merck, Darmstadt, Germany). Magnetic antibody-conjugated beads were prepared by sonicating for $30 \mathrm{sec}-$ onds, followed vortexing for 1 minute to reduce the aggregation of beads. All samples, including the quality control samples and standards, were prepared as recommended in the Milliplex map assay kit protocols. First, $200 \mu \mathrm{L}$ of assay buffer was added to each well. The plate was then allowed to shake on a plate shaker for 10 minutes at room temperature. The assay buffer was thereafter decanted, and 25 $\mu \mathrm{L}$ of each standard/control was added to the appropriate wells. Subsequently, $25 \mu \mathrm{L}$ of treated sample and prepared beads were added to the appropriate wells along with buffering solutions. Each plate was subsequently sealed and incubated overnight at $4^{\circ} \mathrm{C}$. The plates were washed 2 times, followed by the addition of $25 \mu \mathrm{L}$ of detection antibodies to each well. After 1 hour of incubation at room temperature, $25 \mu \mathrm{L}$ of streptavidin-phycoerythrin was added to each well and incubated at room temperature for 30 minutes. The plates were washed twice and finally resuspended in $100 \mu \mathrm{L}$ of sheath fluid in each well.

\section{Liver injury immunoassay protocol}

The rat liver injury magnetic bead panel (catalogue \#RLI1MAG92K) was used to determine the serum expression of 5'-nucleotidase/CD73 (5'-NT), aspartate transaminase 1 (AST) and glutamate oxaloacetate transaminase (GOT-1) and liver-type arginase 1 (ARG-1), according to the manufacturer's instructions (Merck). Standards, control, and background and diluted serum samples ( $25 \mu \mathrm{L}$ each) were added to each well, followed by an assay buffer and mixed antibody-immobilized beads $(25 \mu \mathrm{L})$. The plates were incubated with agitation for 2 hours at room temperature, followed by washing with wash buffer and the addition of $25 \mu \mathrm{L}$ of detection antibodies. The plate was incubated for 1 hour at room temperature. Streptavidin-phycoerythrin $(25 \mu \mathrm{L}$ ) was added to each well, incubated for 30 minutes at room temperature, and washed three times and resuspended in sheath fluid $(150 \mu \mathrm{L})$.

\section{Plate analysis}

Both assay plates were then analyzed with the Bio-Plex MAGPIX Multiplex reader (Bio-Rad Laboratories, Pleasanton, CA, USA) with xPONENT v.3.2 software and further analyzed with BelysaTM Immunoassay Curve Fitting-Software (v1) (Merck).

\section{Statistical analysis}

All statistical analyses were carried out using Stata ver. 10
(StataCorp., College Station, TX, USA). Non-parametric data (blood pressure and proteinuria) are summarized as medians and interquartile ranges, and parametric data are presented as mean and standard deviation. The Kruskal-Wallis and Dunn post hoc tests were used to compare the medians between groups and to determine statistical significance. One-way analysis of variance followed by a pair-wise comparison of means was used to determine whether significant differences existed among the groups. Pearson correlation coefficients were also used to assess the relationship between TGF- $\beta$ and liver injury enzymes, and to estimate whether TGF levels depended on the expression of liver enzymes. A $p$-value $<0.05$ was considered to indicate statistical significance.

\section{Results}

Changes in systolic (Figure 1A) and diastolic (Figure 1B) blood pressure, urinary protein levels (Figure 1C), liver and placental weight (Figure 1D-F) and birth outcomes (Figure 1G and H) are shown. Significant elevations were noted in both the systolic and diastolic blood pressure in the PAVP group in comparison to the NS and PS groups at GD8 $(p<0.05), \operatorname{GD} 14(p<0.001)$, and GD18 $(p<0.001)$ (Figure $1 A$ and $B$ ). Liver weight was significantly higher in the PAVP group than in the NAVP group $(p<0.001)$ (Figure 1D). Placental weight (individual and total) was significantly lower in the PAVP group than in the saline groups $(p<0.05)$ (Figure $1 E$ and F). Additionally, weight per pup was significantly lower in the AVP-treated group than in the saline group $(p<0.05)$ (Figure 1G); however, the PAVP rats demonstrated significantly higher pup numbers than the NAVP group $(p<0.05)$ (Figure 1H).

The mean serum levels of TGF- $\beta(1,2$ and 3$)$ and liver toxicity indicators (ARG-1, GOT-1/AST, and 5'-NT) for all groups are shown in Figure 2. Notably, TGF- $\beta 2$ and TGF- $\beta 3$ levels were significantly downregulated in the non-pregnant rats (saline and AVP) versus the pregnant rats (Figure 2B and C). However, only TGF- $\beta 2$ was significantly different between the PAVP rats and the PS rats $(p<0.001)$ (Figure 2B). In contrast, no observable difference was noted between these pregnant groups for TGF- $\beta 1$ and TGF- $\beta 3$, regardless of AVP treatment (Figure 2A and C). Serum GOT-1 (AST) levels were significantly lower in the PAVP rats than in the non-pregnant controls (Figure 2E). Despite the lack of statistical significance, GOT-1 (AST) levels were lower in the PAVP rats than in the PS group (Figure 2E). Circulating ARG-1 and 5 -NT levels were significantly higher in the PAVP rats than in the PS rats $(p<0.05)$ (Figure 2D and F). In the PAVP group, ARG-1 levels were significantly higher than the NAVP group (Figure 2D), whereas 5'-NT levels were higher in the NAVP group than in the PAVP group (Figure 2F).

The Pearson correlation analysis revealed a negative association 
A

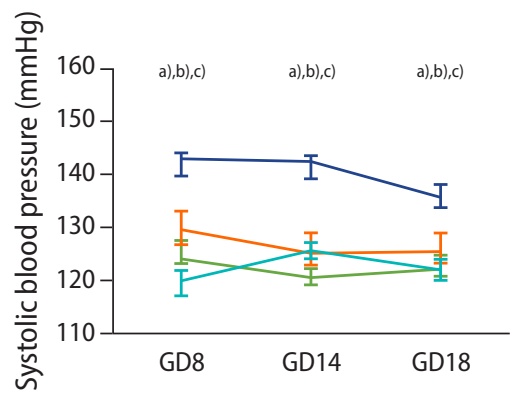

D

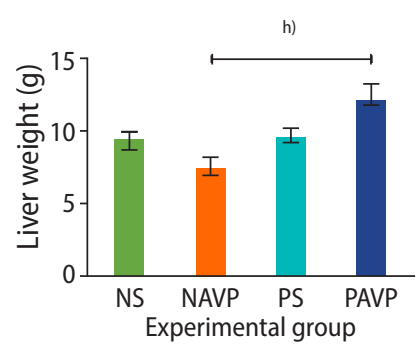

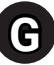

G
B

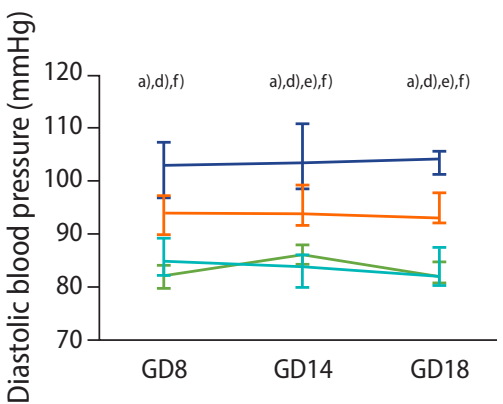

C

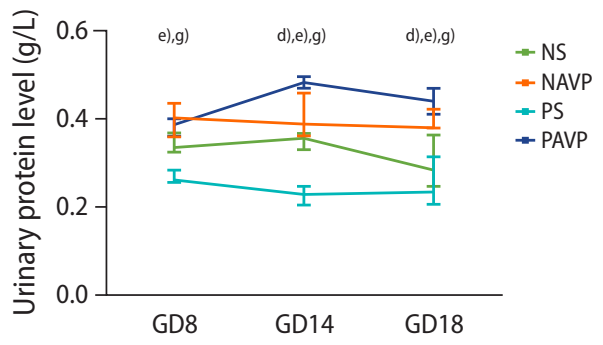

E

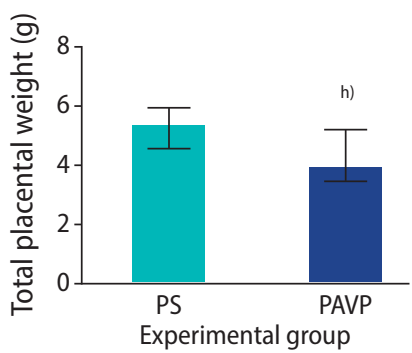

F

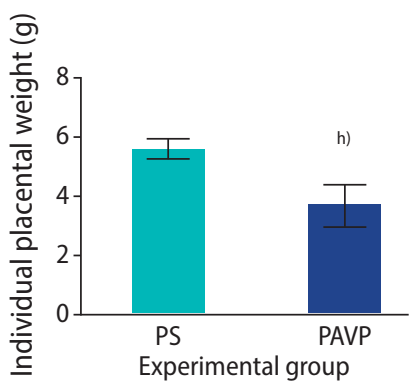

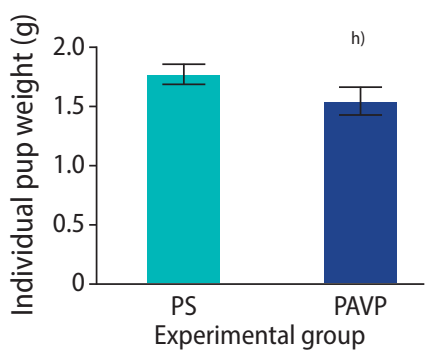

H

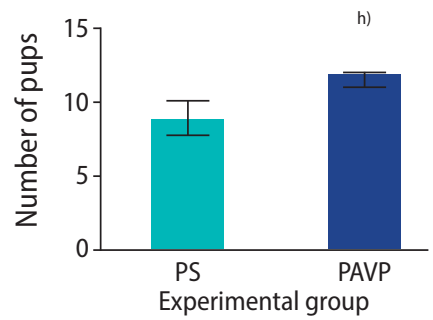

Figure 1. (A) Systolic blood pressure. (B) Diastolic blood pressure. (C) Urinary protein levels. (D) Liver weight (GD18). (E, F) Placental weight. $(G, H)$ Pup weight. Summary statistics are presented as median and interquartile range $(A-C)$ and mean \pm standard deviation (D-H). $G D$, gestational day; NS, non-pregnant saline control; NAVP, nonpregnant arginine vasopressin; PS, pregnant saline control; PAVP, pregnant arginine vasopressin. ${ }^{\text {a) }} p<0.001$ : PAVP vs. PS; ${ }^{\text {b) }} p<0.05$ : PAVP vs. NS; ${ }^{C)} p<0.05$ : PAVP vs. NAVP; ${ }^{\text {d) }} p<0.001$ : PAVP vs. NS; ${ }^{\text {e) }} p<0.05:$ NAVP vs. PS; f) $p<0.05$ : NAVP vs. NS; ${ }^{g)} p<0.05$ : PAVP vs. PS; ${ }^{\text {h) }} p<0.05$.

between TGF- $\beta 1$ and 5'-NT in the PAVP group $(r=-0.85, p=0.15)$ and between TGF- $\beta 1$ and 5'-NT in the NAVP group ( $r=-0.75$, $p=0.25$ ), as well as a positive association between TGF- $\beta 2$ and ARG1 in the PS $(r=0.18, p=0.78)$ and PAVP rats $(r=0.44, p=0.56)$, albeit non-significant.

\section{Discussion}

This novel study demonstrates an apparently paradoxical synergy between TGF- $\beta$ dysregulation and liver injury in pregnant rats treated with AVP. Similar to the report by Santillan et al. [21], the experi- mental use of AVP elevated blood pressure in treated groups, and animals displayed the characteristic features of PE. Our data showed mild elevation of blood pressure (systolic and diastolic) and proteinuria in the PAVP group compared to the other study groups. This elevation is linked to the physiological role of AVP in promoting water reabsorption, which in excess will elevate blood pressure [22]. The AVP-induced elevation in blood pressure indicates low levels of circulating renin-angiotensin system activity, which decreases blood flow through its vasoconstrictive action on V1a receptors and V2 receptors [23]. This reduced blood flow may have resulted in low pup weights, mirroring the placental-related fetal growth restriction ob- 
A

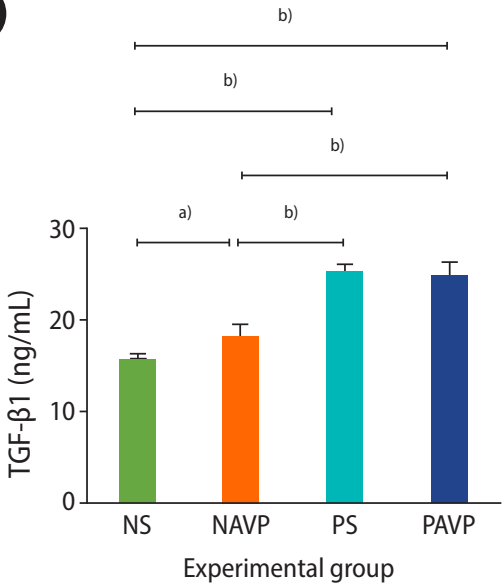

(D)

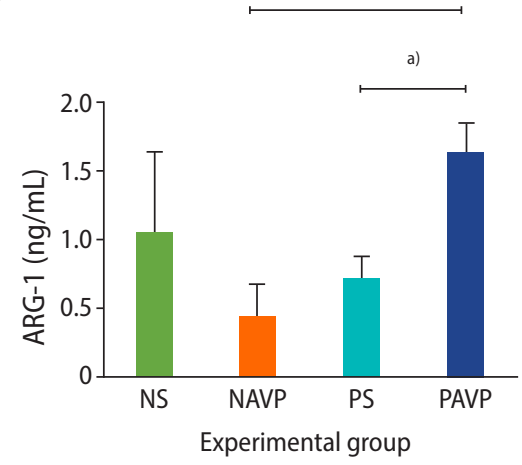

B

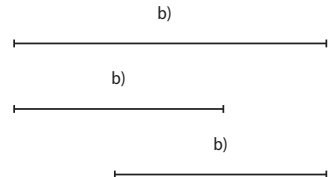

b)

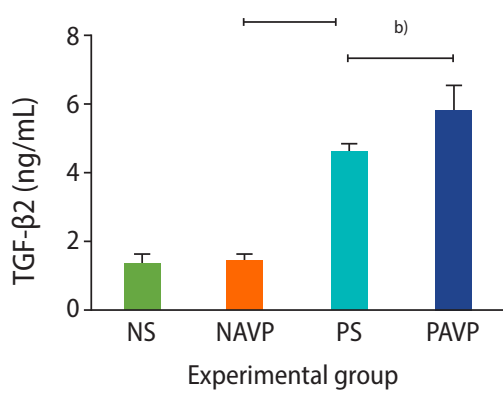

E

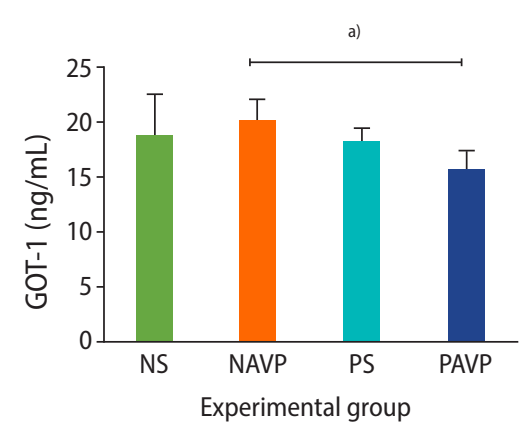

C

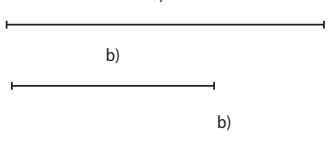

b)
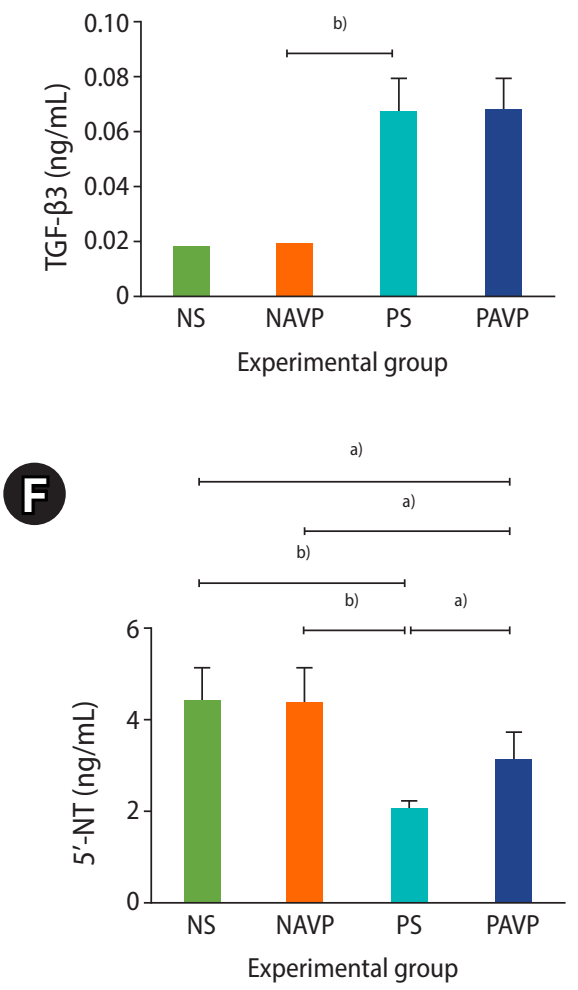

Figure 2. Serum expression of TGF- $\beta$ ( $A: 1, B: 2$, and $C: 3$ ) and liver toxicity indicators (D: ARG-1, E: GOT-1/AST, and F: $5^{\prime}-N T$ ). Summary statistics are presented as mean \pm standard deviation. TGF- $\beta$, transforming growth factor beta; ARG-1, arginase 1 ; GOT-1, glutamate oxaloacetate transaminase; 5'-NT, 5'-nucleotidase/CD73; NS, non-pregnant saline control; NAVP, non-pregnant arginine vasopressin; PS, pregnant saline control; PAVP, pregnant arginine vasopressin; AST, aspartate transaminase. ${ }^{\text {al }} p<0.05$; ${ }^{\text {b) }} p<0.01$.

served in human PE [24]. Moreover, uncontrolled high blood pressure leads to glomerular damage and resulting protein leakage [25].

TGF- $\beta$ isoforms regulate placentation and cell growth, survival, and death during pregnancy $[26,27]$, as well as enhance the differentiation and invasiveness of trophoblast cells in rat pregnancies [28]. Serum TGF- $\beta$ levels are higher in women with PE than in those with normotensive pregnancies $[13,29,30]$. However, TGF- $\beta 1$ expression is variable in $\mathrm{PE}[31,32]$, which may reflect population-level differences in ethnicity, as well as variation in PE severity [33]. We highlight similar TGF- $\beta 1$ and TGF- $\beta 3$ levels in the PS and PAVP rats, whereas TGF- $\beta 2$ levels were significantly higher in the PAVP rats. Our results corroborate those of Shaarawy et al. [30], who demonstrated significantly higher maternal serum TGF- $\beta 2$ levels in PE cases compared to controls. The disproportionate expression of TGF- $\beta 2$ in our study may be associated with reduced blood flow, which accounted for the reduced placental weight in AVP-treated pregnancies. It is possible that AVP-associated vasoconstriction alters placentation via elevated apoptosis of invasive trophoblast cells. Additionally, these elevations may be linked to a high placental affinity for TGF- $\beta$ receptor, indicative of its role as a prime target for TGF- $\beta$ action [34].

On the contrary, AVP infusion was found to result in a pro-inflammatory environment and a reduction in plasma TGF- $\beta$ levels [35], contradicting the findings of our study, possibly due to the lack of specification of individual isoforms in that study. However, this pro-inflammatory environment potentially leads to poor placental development [21], and supposedly enhances the reaction of the renin-angiotensin system [36]. However, Sandgren et al. [37] highlighted the inability of AVP to create a hypoxic environment. This likely interrupts placental development, resulting in the similar TGF- $\beta 1$ and TGF- $\beta 3$ expression observed in our study. Moreover, the lack of a hypoxic environment may have also counteracted the placental secretion of the other TGF- $\beta$ isoforms, as well as contributed to significantly higher pup numbers than in the saline groups.

Additionally, to verify whether the AVP infusion altered the liver 
function in this rat model, the circulating levels of liver injury enzymes were measured. Our data indicate that AVP-infused pregnant rats expressed higher ARG-1 and 5'-NT levels than their saline-treated counterparts. This elevation suggest some level of liver injury induced by AVP, but the liver injury was insufficient to model the hepatic dysfunction linked to HELLP syndrome, corroborating the findings of Sandgren's group [37]. Since TGF- $\beta$ isoforms are profibrogenic in nature, they may also have an inhibitory action on the progression of liver injury [19]. Although pregnancy-initiated liver diseases such as HELLP syndrome and acute fatty liver disease are infrequent, their diagnosis should not be ruled out due to the possibility of acute liver failure, which contributes to maternal and neonatal mortality [38]. The cytosolic enzyme arginase I is significantly expressed in vascular endothelial and smooth muscle cells and responsible for urea metabolism in the liver [39]. It reciprocally regulates the synthesis of NO through L-arginine as the NO synthase substrate [40] and its reduced bioavailability is associated with endothelial dysfunction and the etiology of hypertension $[41,42]$.

We report significantly higher ARG-1 and 5'-NT in the PAVP group than in the control groups. It is possible that the elevation in ARG-1 may be linked to its role as a protagonist in fibrosis, immunosuppression, and inflammatory-derived immune anomalies [43]. Moreover, its increased expression in the PAVP rats is indicative of its role in inducing an inflammatory response. Earlier in vivo reports also suggested that activation of murine macrophages by interleukins $(4,10$, and 13) was associated with elevated arginase expression [44-46]. Bagnost et al. [39] also demonstrated raised arginase activity in the larger blood vessels, heart, and lungs of spontaneously hypertensive rats (SHR), however, they were unable to demonstrate any significant difference in tissue arginase activity between prehypertensive SHRs and Wistar-Kyoto rats.

The membrane glycoprotein $5^{\prime}$-NT is increased in the serum of patients with hepatobiliary disease, hepatitis, intrinsic liver damage, liver malignancy, and biliary cirrhosis [47], indicating that 5'-NT may be clinically relevant as a risk indicator for identifying those vulnerable to liver disease. Hence, the AVP-induced elevations in 5'-NT observed in the PAVP rats in contrast to the PS rats may be associated with hepatobiliary disease, as previously reported [48]. An increase in 5'NT in AVP-induced pregnancies is suggestive of some level of hepatotoxicity, supporting the role of 5'-NT as a possible predictor of hepatobiliary lesions and hepatotoxicity [49]. Gowda et al. [50] linked elevated 5'-NT levels to obstructive jaundice and parenchymal liver disease, with the potential for it to be a biomarker of premature hepatic tumors. More recently, Hyde et al. [51] demonstrated a 3-fold increase in the circulating levels of 5'-NT in patients with viral hepatitis and a two-fold increase in patients with liver cirrhosis in comparison to control participants. The elevated levels we observed may be linked to liver inflammation, which occurred in response to the AVP-induced high blood pressure and associated reduced blood flow that lowered placental and individual pup weight, characteristic of mild PE development. With regard to AST/GOT-1, our data showed little or no difference in their serum expression in the PS group versus the non-pregnant groups, corroborating several other studies $[52,53]$, where levels of this enzyme remained within normal limits.

The onset of fibrosis occurs due to elevated collagen deposition and insufficient ECM associated with the shift from fibroblasts to myofibroblasts [11]. We also report various positive associations between TGF- $\beta$ and liver enzymes, supporting their role in hepatocyte injury and wound healing via transdifferentiation of hepatic stellate cells into myofibroblasts [19]. This transition is believed to be facilitated through the increased production of ECM collagen fibers and a-smooth muscle actin (a-SMA) [11,54]. Nonetheless, fibrosis may also occur due to an endothelial-to-mesenchymal shift [55], since a-SMA, which is typically expressed in vascular smooth muscle cells, stimulates collagen type I formation through autocrine stimulation of TGF- $\beta 1$ [56]. The negative associations between TGF- $\beta 1$ and ARG1 in the PS and PAVP groups may be suggestive of fibroblast differentiation into myofibroblasts, which negatively regulates ARG-1 synthesis.

This is the first study to demonstrate AVP-induced elevations in TGF- $\beta 2$, ARG-1, and 5'-NT activity in pregnant rats treated with AVP in contrast to untreated pregnant rats. AVP likely causes vasoconstriction, which increases peripheral resistance and blood pressure, potentially inducing TGF- $\beta$ elevation and the inflammatory response associated with PE development. This suggests its potential diagnostic use in PE development; however, its prognostic effect remains to be elucidated. Future studies should explore the mechanisms through which AVP dysregulates liver injury enzymes and TGF- $\beta$ in pregnant rats.

\section{Conflict of interest}

No potential conflict of interest relevant to this article was reported.

\section{Acknowledgments}

The authors wish to thank Dr. S Baijnath for his assistance with the animal work and acknowledge the Biomedical Research Unit for their use of the facilities.

\section{ORCID}

Nalini Govender https://orcid.org/0000-0002-4047-6340 
Sapna Ramdin

Rebecca Reddy

Thajasvarie Naicker

https://orcid.org/0000-0003-0166-2842

https://orcid.org/0000-0003-4400-599X

https://orcid.org/0000-0001-6917-2191

\section{Author contributions}

Conceptualization: NG, TN. Formal analysis: SR, NG. Funding acquisition: NG. Methodology: SR, RR. Writing-original draft: NG. Writingreview \& editing: NG, TN.

\section{References}

1. Bremer L, Schramm C, Tiegs G. Immunology of hepatic diseases during pregnancy. Semin Immunopathol 2016;38:669-85.

2. Alese MO, Moodley J, Naicker T. Preeclampsia and HELLP syndrome, the role of the liver. J Matern Fetal Neonatal Med 2021;34: 117-23.

3. Mikolasevic I, Filipec-Kanizaj T, Jakopcic I, Majurec I, Brncic-Fischer A, Sobocan N, et al. Liver disease during pregnancy: a challenging clinical issue. Med Sci Monit 2018;24:4080-90.

4. Valensise H, Vasapollo B, Gagliardi G, Novelli GP. Early and late preeclampsia: two different maternal hemodynamic states in the latent phase of the disease. Hypertension 2008;52:873-80.

5. Frishman WH, Schlocker SJ, Awad K, Tejani N. Pathophysiology and medical management of systemic hypertension in pregnancy. Cardiol Rev 2005;13:274-84.

6. Koyama Y, Brenner DA. Liver inflammation and fibrosis. J Clin Invest 2017;127:55-64.

7. Brown MA, Magee LA, Kenny LC, Karumanchi SA, McCarthy FP, Saito S, et al. Hypertensive disorders of pregnancy: ISSHP classification, diagnosis, and management recommendations for international practice. Hypertension 2018;72:24-43.

8. Aggarwal PK, Chandel N, Jain V, Jha V. The relationship between circulating endothelin-1, soluble fms-like tyrosine kinase-1 and soluble endoglin in preeclampsia. J Hum Hypertens 2012;26: 236-41.

9. Shibuya M. Vascular endothelial growth factor receptor-1 (VEGFR-1/F(t-1): a dual regulator for angiogenesis. Angiogenesis 2006;9:225-30.

10. Levine RJ, Maynard SE, Qian C, Lim KH, England LJ, Yu KF, et al. Circulating angiogenic factors and the risk of preeclampsia. N Engl J Med 2004;350:672-83.

11. Vallee $A$, Lecarpentier Y. TGF- $\beta$ in fibrosis by acting as a conductor for contractile properties of myofibroblasts. Cell Biosci 2019;9:98.

12. Venkatesha S, Toporsian M, Lam C, Hanai J, Mammoto T, Kim YM, et al. Soluble endoglin contributes to the pathogenesis of preeclampsia. Nat Med 2006;12:642-9.

13. Adu-Gyamfi EA, Lamptey J, Duan F, Wang YX, Ding YB. The transforming growth factor $\beta$ superfamily as possible biomarkers of preeclampsia: a comprehensive review. Biomark Med 2019;13: 1321-30.

14. Toporsian M, Gros R, Kabir MG, Vera S, Govindaraju K, Eidelman $\mathrm{DH}$, et al. A role for endoglin in coupling eNOS activity and regulating vascular tone revealed in hereditary hemorrhagic telangiectasia. Circ Res 2005;96:684-92.

15. Munger JS, Sheppard D. Cross talk among TGF- $\beta$ signaling pathways, integrins, and the extracellular matrix. Cold Spring Harb Perspect Biol 2011;3:a005017.

16. Chambaz EM, Souchelnitskiy S, Pellerin S, Defaye G, Cochet C, Feige JJ. Transforming growth factors-beta s: a multifunctional cytokine family: implication in the regulation of adrenocortical cell endocrine functions. Horm Res 1996;45:222-6.

17. Lyall F, Simpson H, Bulmer JN, Barber A, Robson SC. Transforming growth factor-beta expression in human placenta and placental bed in third trimester normal pregnancy, preeclampsia, and fetal growth restriction. Am J Pathol 2001;159:1827-38.

18. August $P$, Leventhal $B$, Suthanthiran M. Hypertension-induced organ damage in African Americans: transforming growth factor-beta(1) excess as a mechanism for increased prevalence. Curr Hypertens Rep 2000;2:184-91.

19. Dooley S, ten Dijke P. TGF- $\beta$ in progression of liver disease. Cell Tissue Res 2012;347:245-56.

20. Girling JC, Dow E, Smith JH. Liver function tests in pre-eclampsia: importance of comparison with a reference range derived for normal pregnancy. Br J Obstet Gynaecol 1997;104:246-50.

21. Santillan MK, Santillan DA, Scroggins SM, Min JY, Sandgren JA, Pearson NA, et al. Vasopressin in preeclampsia: a novel very early human pregnancy biomarker and clinically relevant mouse model. Hypertension 2014;64:852-9.

22. Bankir L, Bichet DG, Morgenthaler NG. Vasopressin: physiology, assessment Oand osmosensation. J Intern Med 2017;282:284-97.

23. Bourque CW. Central mechanisms of osmosensation and systemic osmoregulation. Nat Rev Neurosci 2008;9:519-31.

24. Burton GJ, Jauniaux E. Pathophysiology of placental-derived fetal growth restriction. Am J Obstet Gynecol 2018;218(2S):S745-61.

25. Drawz PE, Rosenberg ME. Slowing progression of chronic kidney disease. Kidney Int Suppl (2011) 2013;3:372-6.

26. Caniggia I, Grisaru-Gravnosky S, Kuliszewsky M, Post M, Lye SJ. Inhibition of TGF-beta 3 restores the invasive capability of extravillous trophoblasts in preeclamptic pregnancies. J Clin Invest 1999; 103:1641-50.

27. Adu-Gyamfi EA, Ding YB, Wang YX. Regulation of placentation by the transforming growth factor beta superfamily. Biol Reprod 2020;102:18-26. 
28. Lafontaine L, Chaudhry P, Lafleur MJ, Van Themsche C, Soares MJ, Asselin E. Transforming growth factor Beta regulates proliferation and invasion of rat placental cell lines. Biol Reprod 2011;84:553-9.

29. Li Q. Transforming growth factor $\beta$ signaling in uterine development and function. J Anim Sci Biotechnol 2014;5:52.

30. Shaarawy M, El Meleigy M, Rasheed K. Maternal serum transforming growth factor beta-2 in preeclampsia and eclampsia, a potential biomarker for the assessment of disease severity and fetal outcome. J Soc Gynecol Investig 2001;8:27-31.

31. Perucci LO, Gomes KB, Freitas LG, Godoi LC, Alpoim PN, Pinheiro $\mathrm{MB}$, et al. Soluble endoglin, transforming growth factor-Beta 1 and soluble tumor necrosis factor alpha receptors in different clinical manifestations of preeclampsia. PLoS One 2014;9:e97632.

32. Huber A, Hefler L, Tempfer C, Zeisler H, Lebrecht A, Husslein P. Transforming growth factor-beta 1 serum levels in pregnancy and pre-eclampsia. Acta Obstet Gynecol Scand 2002;81:168-71.

33. Peracoli MT, Menegon FT, Borges VT, de Araujo Costa RA, Thomazini-Santos IA, et al. Platelet aggregation and TGF-beta(1) plasma levels in pregnant women with preeclampsia. J Reprod Immunol 2008;79:79-84.

34. Gregory AL, Xu G, Sotov V, Letarte M. Review: the enigmatic role of endoglin in the placenta. Placenta 2014;35 Suppl:S93-9.

35. Scroggins SM, Santillan DA, Lund JM, Sandgren JA, Krotz LK, Hamilton WS, et al. Elevated vasopressin in pregnant mice induces T-helper subset alterations consistent with human preeclampsia. Clin Sci (Lond) 2018;132:419-36.

36. Harmon AC, Cornelius DC, Amaral LM, Faulkner JL, Cunningham MW Jr, Wallace K, et al. The role of inflammation in the pathology of preeclampsia. Clin Sci (Lond) 2016;130:409-19.

37. Sandgren JA, Deng G, Linggonegoro DW, Scroggins SM, Perschbacher KJ, Nair AR, et al. Arginine vasopressin infusion is sufficient to model clinical features of preeclampsia in mice. JCI Insight 2018;3:e99403.

38. Schutt VA, Minuk GY. Liver diseases unique to pregnancy. Best Pract Res Clin Gastroenterol 2007;21:771-92.

39. Bagnost T, Berthelot A, Alvergnas M, Miguet-Alfonsi C, Andre C, Guillaume $Y$, et al. Misregulation of the arginase pathway in tissues of spontaneously hypertensive rats. Hypertens Res 2009:32:1130-5.

40. Berkowitz DE, White R, Li D, Minhas KM, Cernetich A, Kim S, et al. Arginase reciprocally regulates nitric oxide synthase activity and contributes to endothelial dysfunction in aging blood vessels. Circulation 2003;108:2000-6.

41. Landmesser U, Drexler H. Endothelial function and hypertension.
Curr Opin Cardiol 2007;22:316-20.

42. Toque HA, Nunes KP, Rojas M, Bhatta A, Yao L, Xu Z, et al. Arginase 1 mediates increased blood pressure and contributes to vascular endothelial dysfunction in deoxycorticosterone acetate-salt hypertension. Front Immunol 2013;4:219.

43. Bronte V, Zanovello P. Regulation of immune responses by L-arginine metabolism. Nat Rev Immunol 2005;5:641-54.

44. Louis CA, Mody V, Henry WL Jr, Reichner JS, Albina JE. Regulation of arginase isoforms I and II by IL-4 in cultured murine peritoneal macrophages. Am J Physiol 1999;276:R237-42.

45. Munder M, Eichmann K, Moran JM, Centeno F, Soler G, Modolell M. Th1/Th2-regulated expression of arginase isoforms in murine macrophages and dendritic cells. J Immunol 1999;163:3771-7.

46. Chang Cl, Zoghi B, Liao JC, Kuo L. The involvement of tyrosine kinases, cyclic AMP/protein kinase A, and p38 mitogen-activated protein kinase in IL-13-mediated arginase I induction in macrophages: its implications in IL-13-inhibited nitric oxide production. J Immunol 2000;165:2134-41.

47. Arika WM, Nyamai DW, Osano KO, Ngugi MP, Njagi EN. Biochemical markers of in vivo hepatotoxicity. J Clin Toxicol 2016;6:e1000297.

48. Dixon TF, Purdom M. Serum 5-nucleotidase. J Clin Pathol 1954; 7:341-3.

49. Carakostas MC, Power RJ, Banerjee AK. Serum 5'nucleotidase activity in rats: a method for automated analysis and criteria for interpretation. Vet Clin Pathol 1990;19:109-113.

50. Gowda S, Desai PB, Hull VV, Math AA, Vernekar SN, Kulkarni SS. A review on laboratory liver function tests. Pan Afr Med J 2009;3:17.

51. Hyder MA, Hasan M, Mohieldein A. Comparative study of 5'-nucleotidase test in various liver diseases. J Clin Diagn Res 2016;10:BC01-3.

52. Westbrook RH, Dusheiko G, Williamson C. Pregnancy and liver disease. J Hepatol 2016;64:933-45.

53. Shekhar S, Diddi G. Liver disease in pregnancy. Taiwan J Obstet Gynecol 2015;54:475-82.

54. Froese AR, Shimbori C, Bellaye PS, Inman M, Obex S, Fatima S, et al. Stretch-induced activation of transforming growth factor- $\beta 1$ in pulmonary fibrosis. Am J Respir Crit Care Med 2016;194:84-96.

55. Piera-Velazquez S, Mendoza FA, Jimenez SA. Endothelial to mesenchymal transition (EndoMT) in the pathogenesis of human fibrotic diseases. J Clin Med 2016;5:45.

56. Douillet CD, Velarde V, Christopher JT, Mayfield RK, Trojanowska ME, Jaffa AA. Mechanisms by which bradykinin promotes fibrosis in vascular smooth muscle cells: role of TGF-beta and MAPK. Am J Physiol Heart Circ Physiol 2000;279:H2829-37. 